\title{
The quest for a more acceptable bowel preparation: comparison of a polyethylene glycol/electrolyte solution and a mannitol/Picolax mixture for colonoscopy
}

Brian P Saunders, Tadahiko Masaki, Manabu Fukumoto, Steven Halligan, Christopher B Williams

\section{Summary}

Eighty-nine consecutive patients attending for day-case colonoscopy were randomly allocated either polyethylene glycol/balanced electrolyte (PEG) mixture $(n=45)$ or a mannitol/Picolax mixture $(n=44)$. Both preparations were administered in two fractions. Patients recorded their experience of the preparation on a questionnaire and one of two experienced endoscopists (unaware of the type of preparation given) assessed the result of bowel cleansing. Carbon dioxide insufflation was used for all examinations.

Good/excellent bowel cleansing occurred in significantly more patients given PEG, 43 (96\%), than those allocated mannitol/Picolax, 34 (77\%), $p=0.01$. More patients receiving mannitol/Picolax were able to complete the preparation in full than patients receiving PEG (38 vs $27, p=0.01$ ). More patients found the taste of mannitol/Picolax pleasant compared to PEG (46\% vs $20 \%$ ). Both preparations had a similar side-effect profile. Of those patients tested, $13 \%$ receiving mannitol/ Picolax had a postural drop in blood pressure and blood parameters suggestive of mild dehydration.

$A$ fractionated administration of PEG as a bowel preparation for day-case colonoscopy is well tolerated and superior as a cleansing agent to a mannitol/Picolax combination. Provided carbon dioxide is used as the insufflating agent, mannitol/ Picolax is an acceptable alternative in fit, young patients intolerant of PEG.

Keywords: bowel cleansing, colonoscopy

Department of

Endoscopy, St Mark's

Hospital, City Road,

London EC1V 2PS, UK

BP Saunders

T Masaki

M Fukumoto

S Halligan

CB Williams

\section{Introduction}

Adequate bowel preparation is a prerequisite for safe and accurate colonoscopy. To be successful the preparation must be both acceptable to the patient and effective in cleansing the bowel. Traditional preparations involve dietary restriction for several days followed by a purge (often with castor oil) and one or more enemas. ${ }^{1}$ Though effective, purge and enema regimes are time-consuming for patient and endoscopy staff alike and have been replaced by more rapid oral methods of bowel preparation. Oral lavage with either polyethylene glycol/ balanced electrolyte solution (PEG) or magnesium citrate has gained widespread acceptability in the UK. ${ }^{2-4}$ In several clinical trials PEG has been shown to consistently produce good bowel cleansing in a high percentage of patients. ${ }^{2,5-7}$ However, some individuals are unable to tolerate PEG because of the large volume of solution necessary for cleansing and the inherent salty taste of the mixture. ${ }^{8-10}$ In contrast, magnesium citrate (Picolax) is well tolerated by patients but results in a higher failure rate compared to PEG. ${ }^{9}$

It has been our experience over several years that a mixture of magnesium citrate with mannitol (mannitol/Picolax) produces a sweet, lowvolume $(2 \times 500 \mathrm{ml}$ fractions $)$ lemon-tasting solution that is both well tolerated and effective in cleansing the bowel. No study has previously investigated the possible benefits of mannitol/ Picolax mixture. We therefore decided to assess the efficacy, acceptability and safety of mannitol/Picolax by comparing it to PEG as a bowel preparation for day-case colonoscopy.

\section{Materials and methods}

Eighty-nine consecutive patients attending for day-case colonoscopy were randomised to receive either 41 of PEG/electrolyte oral lavage (polyethylene glycol $236 \mathrm{~g}$, sodium sulphate
Common methods of bowel preparation

- purge + enema regimens (castor oil/senna/bisacodyl + phosphate enema(s) $+2-4$ day dietary restriction)

- Picolax (Picolax 2 sachets \pm dietary restriction)

- Picolax + senna (Picolax $1 \frac{1}{2}-2$ sachets + senna \pm dietary restriction)

- sodium phosphate (an osmotic cathartic given in two 90-ml administrations - under consideration for licence in the UK) 
$22.74 \mathrm{~g}$, sodium chloride $5.86 \mathrm{~g}$, potassium chloride $2.97 \mathrm{~g}$, aspartamine $0.2 \mathrm{~g}$; Kleanprep, Norgine Ltd, Oxford, UK) or one litre of mannitol/Picolax mixture (mannitol $100 \mathrm{mg}$, sodium picosulphate $10 \mathrm{mg}$, magnesium oxide $3 \mathrm{~g}$, citric acid $12 \mathrm{~g}$ ). All patients were allowed a normal diet until the afternoon before the day of colonoscopy and thereafter clear fluids only. Patients receiving PEG were given the option of chilling the solution which was then drunk according to the following protocol. Those patients with a morning appointment $(n=4)$

Table 1 Patients' experience of bowel preparation

\begin{tabular}{|c|c|c|c|}
\hline & $\begin{array}{l}P E G \\
(n=45)\end{array}$ & $\begin{array}{l}\text { Mannitol/Picolax } \\
(n=44)\end{array}$ & probability \\
\hline \multicolumn{4}{|c|}{ Ability to complete preparation } \\
\hline full & 27 & 38 & \multirow{3}{*}{$\begin{array}{l}\mathrm{p}=0.01 \\
\mathrm{NS} \\
\mathrm{NS}\end{array}$} \\
\hline$>$ half & 14 & 5 & \\
\hline$<$ half & 4 & 1 & \\
\hline \multicolumn{4}{|c|}{ Overall impression } \\
\hline no problem & 34 & 34 & \multirow{3}{*}{ NS } \\
\hline bothersome & 9 & 6 & \\
\hline distressing & 2 & 4 & \\
\hline \multicolumn{4}{|l|}{ Taste } \\
\hline pleasant & 9 & 20 & \multirow{3}{*}{$\begin{array}{l}\mathrm{p}=0.01 \\
\mathrm{NS} \\
\mathrm{NS}\end{array}$} \\
\hline tolerable & 26 & 20 & \\
\hline unpleasant & 10 & 4 & \\
\hline \multicolumn{4}{|l|}{ Vomiting } \\
\hline none & 42 & 40 & \multirow{3}{*}{ NS } \\
\hline mild & 1 & 3 & \\
\hline severe & 2 & 1 & \\
\hline \multicolumn{4}{|l|}{ Nausea } \\
\hline none & 28 & 24 & \multirow{3}{*}{ NS } \\
\hline mild & 12 & 12 & \\
\hline severe & 5 & 8 & \\
\hline \multicolumn{4}{|l|}{ Fullness } \\
\hline none & 22 & 28 & \multirow{3}{*}{ NS } \\
\hline mild & 13 & 8 & \\
\hline severe & 10 & 8 & \\
\hline \multicolumn{4}{|l|}{ Dizziness } \\
\hline none & 36 & 32 & \multirow{3}{*}{ NS } \\
\hline mild & 6 & 7 & \\
\hline severe & 3 & 5 & \\
\hline \multicolumn{4}{|c|}{ Peri-anal soreness } \\
\hline none & 10 & 20 & \multirow{3}{*}{ NS } \\
\hline mild & 23 & 14 & \\
\hline severe & 12 & 10 & \\
\hline \multicolumn{4}{|c|}{ Sleep disturbance } \\
\hline none & 28 & 27 & \multirow{3}{*}{ NS } \\
\hline mild & 9 & 5 & \\
\hline severe & 8 & 2 & \\
\hline \multicolumn{4}{|c|}{ Abdominal cramps } \\
\hline none & 32 & 31 & \multirow{3}{*}{ NS } \\
\hline mild & 9 & 8 & \\
\hline severe & 4 & 5 & \\
\hline
\end{tabular}

Table 2 Endoscopist's assessment of bowel preparation

\begin{tabular}{lll}
\hline & $\begin{array}{l}P E G \\
(n=45)\end{array}$ & $\begin{array}{l}\text { Mannitol/Picolax } \\
(n=44)\end{array}$ \\
\hline $\begin{array}{l}\text { EXCELLENT: no more than small quan- } \\
\text { tities of clear fluid present }\end{array}$ & 15 & 10 \\
$\begin{array}{l}\text { GOOD: small amounts of fluid residue, } \\
\text { easily suctioned allowing a completely } \\
\text { reliable examination }\end{array}$ & 28 & 24 \\
$\begin{array}{l}\text { FAIR: enough residue, fluid or solid to pre- } \\
\text { vent a completely reliable examination (ie, } \\
\text { small polyps < } 5 \text { mm could not be excluded) }\end{array}$ & 1 & 5 \\
$\begin{array}{l}\text { POOR: large amounts of residue present } \\
\text { making endoscopic view uninterpretable; } \\
\text { additional cleansing required }\end{array}$ & 1 & 5 \\
\hline
\end{tabular}

drank 31 of the solution at a rate of $250 \mathrm{ml} /$ $15 \mathrm{~min}$, starting at $18.00 \mathrm{~h}$ the day before colonoscopy followed by a further 11 at $06.00 \mathrm{~h}$ the following morning. Patients with an afternoon appointment for colonoscopy $(n=41)$ were asked to drink 21 the evening before and 21 on the morning of the procedure. In the mannitol/Picolax group, patients were instructed to drink $500 \mathrm{ml}$ of the chilled solution at $18.00 \mathrm{~h}$ the day before and a further $500 \mathrm{ml}$ at $06.00 \mathrm{~h}$ on the morning of colonoscopy. They were also asked to drink at least $1 \mathrm{l}$ of water in addition to their preparation.

On arrival at the Endoscopy Unit all patients were given a questionnaire asking about their experience of the preparation, including taste, ability to complete the preparation, side-effects encountered and whether or not they would be prepared to repeat the preparation if a future colonoscopy were necessary (table 1 ). In the first 42 patients, lying and standing blood pressures were recorded and a venous blood sample taken for haemoglobin, packed cell volume, urea and electrolytes and serum osmolarity.

One of two experienced colonoscopists (CBW, BPS), who were unaware of the type of preparation given, performed the examinations and scored the degree of bowel cleansing according to the descriptions in table 2. Carbon dioxide was used as the insufflating agent during all examinations.

In the PEG group there were 28 females, and 17 males, age range 27-87 years, median 52 years. In the mannitol/Picolax group there were 22 females and 22 males age range 18-73 years, median 49 years.

\section{STATISTICAL ANALYSIS}

The preparation was allocated to patients according to a randomised block design (block size six) to aid concealment and ensure near uniform allocation to the two treatment groups. Data for cleansing of the colon, taste, ability to complete the preparation and patient sideeffects were assessed using Fisher's exact test after combining the data into 2 by 2 contingency tables. Because of multiple testing, significance demanded a calculated $p$-value of less than 0.01 .

\section{Results}

Forty-five patients were randomised to receive PEG and 44 mannitol/Picolax. The two patient groups were similar with regard to age, sex, indication for colonoscopy, findings at colonoscopy, history of constipation, laxative administration, and drug history. Thirty-eight patients $(86 \%)$ receiving mannitol/Picolax were able to complete their preparation in full as opposed to $27(60 \%)$ given PEG ( $p=0.01)$. More patients found the taste of mannitol/ Picolax 'pleasant' compared to PEG $(46 \%$ vs $20 \%, p=0.01$ ).

There were no significant differences between the two preparations in the incidence of nausea, vomiting, fullness, dizziness, abdominal cramps or peri-anal soreness. When 
asked if they would be prepared to repeat the preparation 39 patients $\left(86^{\circ}\right)$ in the PEG group said they would compared to $41(93 \%)$ in the mannitol/Picolax group (non-significant).

Good or excellent bowel cleansing occurred in significantly more patients receiving PEG $(96 \%)$ than those allocated mannitol/Picolax $(77 \%), p=0.01$. Rescheduling of the procedure and additional cleansing was necessary in one patient in the PEG group but five receiving mannitol/Picolax.

Of the 42 patients who underwent assessment of blood pressure and blood parameters, 20 received PEG and 22 mannitol/Picolax. There was a postural drop in blood pressure (systolic drop of $20 \mathrm{mmHg}$ on standing), raised packed cell volume and raised serum osmolarity in three patients receiving mannitol/Picolax preparation. One patient receiving PEG had a postural drop in blood pressure but this was not accompanied by any biochemical or haematological abnormalities.

\section{Discussion}

An 'ideal' bowel preparation for colonoscopy would be easy to administer, have a rapid onset of action, produce satisfactory cleansing in approaching $100 \%$ of all patients, be cheap, easily packaged and above all be safe and acceptable to the patient. Prior to this study it was our impression that mannitol/Picolax mixture might come close to this ideal. Certainly it is cheap (approximate cost per patient $=$ $£ 0.60 \mathrm{p})$ and easily packaged. This study has also shown mannitol/Picolax mixture to be acceptable to the patient. $91 \%$ recorded its taste as pleasant or tolerable and $86 \%$ were able to complete it in full; probably a consequence of the relatively small volume and split-administration. However, mannitol/Picolax is clearly inferior as a cleansing agent to two-dose PEG even though the $77 \%$ good/excellent cleansing rate compares favourably with preparation by two sachets of Picolax alone. ${ }^{9}$

Recently mannitol has been disregarded as a bowel preparation because of reports that its use may be associated with a build-up of potentially explosive gases. ${ }^{11}$ However the risk of combustion is only present if oxygen is used as the insufflating agent. ${ }^{12} \mathrm{We}$ routinely use carbon dioxide insufflation to reduce postprocedure bloating which therefore allows mannitol to be used safely. Of more concern than a risk of combustion was the finding of clinical and biochemical dehydration in three patients receiving mannitol/Picolax. All were over 60 years old and we would therfore advise caution in prescribing mannitol/Picolax to elderly patients and those with known cardiac or renal problems.

We were surprised to find that such a high percentage $(96 \%)$ of patients receiving PEG had excellent or good cleansing as rated by the endoscopist. This was despite the fact that the

1 Teague RH, Manning AP. Preparation of the large bowel for endoscopy. F Int Med Res 1977; 5: 374-7.

2 Burke DA, Manning AP, Murphy L, Axon ATR. Oral bowel lavage preparation for colonoscopy. Postgrad Med $\mathcal{F}$ 1988; 64: $772-4$.

\section{Properties of the ideal bowel} preparation

- high patient acceptability

- easy administration

- rapid onset of action

- effective in all types of patient

- cheap

- easily packaged

- safe

\section{Learning/summary points}

- PEG is superior to mannitol/Picolax mixture as bowel preparation for day-case colonoscopy

- a fractionated administration of PEG may improve patient tolerability

- mannitol/Picolax is an acceptable bowel preparation in fit, young patients, intolerant of PEG, provided carbon dioxide is available for insufflation

administration had been split into two doses and that $36 \%$ of patients did not complete their preparation in full. PEG was also well tolerated by the majority of our patients, possibly a reflection of the split-administration regime. Rosch et al have demonstrated that a fractionated administration of the PEG mixture is preferred by in-patients asked to drink up to 61 of solution. ${ }^{13}$ Using our 41 split-administration regime in out-patients, we have recorded only a $6 \%$ incidence of vomiting. This compares favourably with studies in which the full 41 is drunk continuously (the currently recommended method of administration), where a $10-20 \%$ incidence of vomiting has been recorded. ${ }^{8,9,14}$ Of the 20 patients who both received PEG and were tested for postural changes in blood pressure and changes in blood parameters, only one patient showed an abnormality: a postural drop in blood pressure in a 56-year-old man who was also taking antihypertensive medication. This low incidence of biochemical or haemodynamic abnormality further emphasises the beneficial safety profile of the PEG mixture. ${ }^{15}$

In conclusion two-dose PEG oral lavage is superior as a cleansing agent to a mannitol/ Picolax mixture. The high patient acceptability of PEG seen in this study is likely to be related to the split administration regime and we would recommend this method of administration when using PEG. For younger patients intolerant of PEG, mannitol/Picolax is an acceptable alternative as bowel preparation for colonoscopy, provided carbon dioxide is used as the insufflating agent during the procedure.

The authors would like to acknowledge the help of Margaret Boland and Michelle Taylor for their help in running this study and Sharon Love for statistical advice.

3 Roe AM, Jamison MH, MacLennan I. Colonoscopy preparation with Picolax. f Coll Surg Edin 1984; 29: 103-4. 4 Brown JJ, Jewell DP. Outpatient preparation for colonoscopy. Lancet 1981; 2: 695 . 
5 Adler M, Quenon M, Even-Adin D, et al. Whole gut lavage for colonoscopy - a comparison between two solutions. Gastrointest Endosc 1984; 30: 65-7.

6 DiPalma JA, Brady CE, Stewart DL, et al. Comparison of colon cleansing methods in preparation for colonoscopy. Gastroenterology 1984; 86: 856-60.

7 Lubowski D, de Carle D, Hunt DR. Colonic lavage with polyethylene glycol. Med f Aust 1985; 142: 256.

8 Hangartner PJ, Munch R, Meir J, et al. Comparison of three colon cleansing methods: evaluation of a randomised clinical trial with 300 ambulatory patients. Endoscopy 1989; 21: 272-5.

9 Dakkak M, Aziz K, Bennett JR. Short report: comparison of two orally administered bowel preparations for colonoscopy two orally administered bowel preparations for colonoscopy - polyethylene glycol and sodium

10 Froehlich F, Fried M, Schnegg JF, et al. Palatability of a new solution compared with standard polyethylene glycol solution for gastrointestinal lavage. Gastrointest Endos 1991; 35: 325-8.
11 Bigard MA, Gaucher P, Lassaile C. Fatal colonic explosion during colonoscopic polypectomy. Gastroenterology 1979 77: $1307-10$

12 Taylor EW, Bentley S, Youngs D, et al. Bowel preparation and the safety of colonoscopic polypectomy. Gastroenterology 1981; 81: 1-4.

13 Rosch T, Classen M. Fractional cleansing of the large bowe with Golytely for colonoscopic preparation: a controlled trial. Endoscopy 1987; 19: 198-200

14 Di Febo G, Gizzi G, Calo G, Siringo S, Brunetti G Comparison of a new colon lavage solution (Iso-Guilliani) with a standard preparation for colonoscopy: a randomised study. Endoscopy 1990; 22: 214-6.

15 Davis GR, Santa Ana CAS, Morawski SG, et al. Development of a lavage solution associated with minimal water and electrolyte absorbtion or secretion. Gastroenterology 1980 78: $991-5$.

Lucien-Marie Pautrier (1876-1959) was born in Marseilles, France. He studied there and in Paris where he became a dermatologist with Louis Brocq at Saint Louis Hospital. His doctorate was an imposing 350-page document on atypical cutaneous tuberculosis (surely sarcoidosis). During the First World War he was in an artillery regiment and was awarded the Cross of Chevalier de la Legion d'Honneur. He became professor of dermatology at Strasbourg and at Lausanne. In his 1939 textbook on sarcoidosis, he opposed the tuberculous theory and regarded it as a reticulo-endotheliosis. He died in Strasbourg on 9 July 1959 and is buried in his birthplace. 